\title{
Water Condition Controls Inclination Angles of Leaflets and Petioles of Soybean (Glycine max L.)
}

\author{
Kiyoshi Nagasuga, Shunsuke Uchida, Hideyuki KaJi, Yuki Hayakawa, Masahide Kadowaki, \\ Atsushi Fukunaga, Sumiyo Nose and Teruhisa UmeZaKi \\ Facility of Bioresources, Mie University, 1577 Kurimamachiya, Tsu, Mie 514-8507, Japan
}

(Received March 22, 2013; Accepted April 30, 2013)

\begin{abstract}
Leaflet inclination angle before paraheliotropism controls seed production of soybean plants. We examined the effect of water condition on the inclination angle of leaflets and petioles of two soybean cultivars. Angles measured in the morning were larger in 2008, a wetter season, than in 2009, a drier season. Angles were similarly larger in irrigated plants than in unirrigated plants. The imposition of drought stress on plants grown in pots reduced these angles with the decline in water content of these tissues. There were significant correlations between inclination angle and water content in leaflets and petioles of plants grown both in the field and in pots. These results indicate that water condition controls leaflet and petiole inclination.
\end{abstract}

Keywords : drought, inclination angle, irrigation, leaflet, petiole, soybean

\section{INTRODUCTION}

Leaf inclination-measured as the angle between the leaf blade and the horizontal plane-is an important agronomic trait of crop plants, as it contributes to plant architecture and grain yields (Sinclair and Sheehy, 1999). Erect leaves of rice plants capture more sunlight (Sinclair and Sheehy, 1999; Saitoh et al., 2002; Soda et al., 2010). Soda et al. (2010) found a close linear relationship between the inclination angle of the leaf blade and the canopy light extinction coefficient in several rice cultivars (including both indica and japonica types) at the heading stage. Erect leaves also store more nitrogen for grain filling and allow denser planting (Sakamoto et al., 2006). Genetic studies of leaf inclination in rice have made remarkable progress, and several associated quantitative trait loci have been reported (Li et al., 1998, 1999; Sakamoto et al., 2006).

The leaflets of legumes, particularly soybean, grow densely in the upper layers of the canopy, restricting light penetration into the lower layers (Sakamoto and Shaw, 1967; Shaw and Weber, 1967; Johnston et al., 1969; Blad and Baker, 1972). In addition, the inclination angle of leaflets changes throughout the day (paraheliotropism, light avoidant movement) in response to environmental stress, such as drought (Shackel and Hall, 1979; Forseth and Ehleringer, 1980; Oosterhuis et al., 1985; Pastenes et al., 2005) and high light intensity (Berg and Heuchelin, 1990). Since paraheliotropic leaf movement protects the photosynthetic apparatus from photoinhibition (Kao and Tsai, 1998; Pastenes et al., 2005) and lets more light into the canopy (Blad and Baker, 1972), many researchers focused more on this movement than the inclination angle of leaflets before paraheliotropism. However, leaflet inclination angle itself (before paraheliotropism) is also an important factor controlling light capture by the whole plant. Kokubun and Watanabe (1981) found that the erectness (vertical) of soybean leaves held by the adhesive tape and steel posts increased light penetration into the canopy and, as a result, seed yield. Since soybean leaves do not have a preferred leaflet inclination before other factors such as paraheliotropism, a large inclination angle (leaflet erectness) as well as paraheliotropism would contribute further to seed production.

In a previous study (Nagasuga et al., 2011b), we compared seed yield, dry matter production, and lightinterception characteristics between the soybean cultivars 'Fukuyutaka' and 'Misato-zairai', which differ in petiole inclination angle and canopy structure. The inclination angle of leaflets before paraheliotropism was smaller in 'Misato-zairai', but the angle also differed between a wetter season and a drier season, and the difference between seasons was larger than that between cultivars (Nagasuga et al., 2011b). These suggested that the inclination angle of soybean leaflets should change in response to water conditions.

In this study, we tested three hypotheses: (1) that the leaflet inclination angle differs between wetter and drier seasons; (2) that the inclination angle responds to changes in soil water condition; and (3) that leaflet inclination angle and leaflet water content show a linear relationship. The angle between the secondary (petiole-petiolule) pulvinus and the leaflet controls paraheliotropism (Mayer et al., 1985; Bielenberg et al., 2003). However, our pervious observation suggested that the inclination of petiole should control that of leaflet before paraheliotropism. So, we also

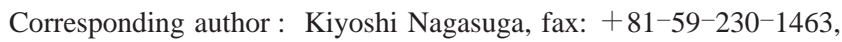
e-mail : nkiyoshi@bio.mie-u.ac.jp 
measured the petiole inclination angle and water content to examine whether the inclination of petiole responded to changes in soil water condition.

\section{MATERIALS AND METHODS}

\section{Field trials}

Crops were surveyed in 2008, 2009, and 2011 on the Farm Station, Mie University $\left(34^{\circ} 81^{\prime} \mathrm{N}, 136^{\circ} 27^{\prime} \mathrm{E}\right)$. 'Fukuyutaka', a popular cultivar in western Japan, and 'Misato-zairai', a local cultivar in Mie prefecture, differ in petiole inclination angle and canopy structure (Nagasuga et al., 2011b). Seeds were sown on 16 July 2008, 14 July 2009, and 8 July 2011 in rows $0.7 \mathrm{~m}$ apart at a spacing of $0.2 \mathrm{~m}$ between plants $\left(7.14\right.$ plants $\left.\mathrm{m}^{-2}\right)$. Four seeds were placed in a 5-cm-deep hole and covered with adjacent soil by hand. After establishment ( 2 wk after emergence), seedlings were thinned to one per position. In each year, basal

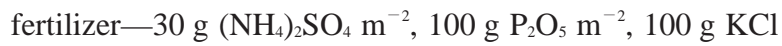
$\mathrm{m}^{-2}$-and $100 \mathrm{~g} \mathrm{~m}^{-2}$ garden lime were applied and mixed into the soil before sowing. Weather conditions, particularly rainfall, differed between 2008 and 2009. Rainfall from sowing to the $\mathrm{R}_{5}$ growth stage (Fehr and Caviness, 1977) was $526.5 \mathrm{~mm}$ in 2008 and $257.5 \mathrm{~mm}$ in 2009 (Table 1). In 2011, the soil surface was covered with clear plastic sheeting to block the rain, and drainage (about $1 \mathrm{~m}$ width $\times 1 \mathrm{~m}$ depth) was dug around the plots. To evaluate the effect of the difference in soil water condition on the inclination angles of leaflets and petioles, we laid irrigation tubes under the plastic and irrigated half of the plants from emergence. Soil water condition in the $20 \mathrm{~cm}$ depth was monitored by time-domain reflectometry (TDR-314F, Fujiwara, Tokyo, Japan). The average soil water content per dry soil weight from establishment to $\mathrm{R}_{5}$ in 2011 was $26.8 \% \mathrm{w} / \mathrm{w}$ in the irrigated plots and $24.9 \%$ in the unirrigated plots. The experiments in 2008 and 2009 used a randomized block design with four replicates; each block was $2.8 \mathrm{~m} \times 3.0 \mathrm{~m}$. The experiments in 2011 used a splitplot design with two levels of irrigation and two cultivars as factors. Each sub-plot $(4.2 \mathrm{~m} \times 4.0 \mathrm{~m})$ had four replicates. At R (3 Oct. 2008, 24 Sep. 2009, 26 Sep. 2011), from each block we selected one representative plant in 2008, two in 2009, and four in 2011 and measured the inclination of third or fourth leaflet and its petiole at 10:00 to 12:00. The inclination was measured as the angle between the horizontal plane and a line from the primary (stempetiole) pulvinus to the secondary pulvinus (petiole) or the tip of the central leaflet (leaflet, Nagasuga et al., 2011b).

\section{Pot trial}

Six seeds of 'Fukuyutaka' and 'Misato-zairai' were planted in 1.4 L-pots $(113 \phi \times 140 \mathrm{~mm}, 1 / 10000$-a Wagner pots; Fujiwara Co., Tokyo, Japan), on 19 May 2009. After

Table 1 Precipitation and mean air temperature during the days from sowing to $\mathrm{R}_{5}$.

\begin{tabular}{ccc}
\hline Year & $\begin{array}{c}\text { Precipitation } \\
(\mathrm{mm})\end{array}$ & $\begin{array}{c}\text { Mean air temperature } \\
\left({ }^{\circ} \mathrm{C}\right)\end{array}$ \\
\hline 2008 & 526.5 & 26.3 \\
2009 & 257.5 & 25.5 \\
\hline
\end{tabular}

emergence, seedlings were thinned to one per pot. Each pot received $2 \mathrm{~g}$ of compound fertilizer $\left(\left(\mathrm{NH}_{4}\right)_{2} \mathrm{SO}_{4}: \mathrm{P}_{2} \mathrm{O}_{5}\right.$ : $\mathrm{KCl}=3: 10: 10)$ and $2 \mathrm{~g}$ of garden lime. The plants were grown in a greenhouse with adequate irrigation. When the sixth leaf appeared $(\sim 1$ month after sowing, rainy season in Japan), irrigation was ceased, and changes in inclination angles (the same leaflets and petioles) and water content (the same leaflets and soil) were monitored every day at 12:00 for $4 \mathrm{~d}$. The leaflet water status was evaluated undestructively with a moisture meter (MY-808S Moisture Checker; Scalar, Tokyo, Japan), and the water content was estimated from a linear regression equation (Nagasuga et al., 2011a). The soil water condition was monitored with the TDR-314F sensor.

\section{Relationship between inclination angle and water} content

Seeds were sown in the unirrigated field on 23 June and 14 July and in pots with adequate irrigation on 15 April and 1 July 2011, and were raised as described above. Firstly, the inclination of third or fourth leaflet and its petiole (excluding paraheliotropic ones) measured at 10: 00 to 12: 00 of the flowering stage (18-30 August in the field) and $\mathrm{V}_{8-12}$ (16-26 June and 4-11 August in pots). Secondly, these were sampled and enclosed by the pre-weighed polyethylene bags quickly. Fresh weight was calculated as the difference between these enclosed ones and pre-weighed polyethylene bags. Finally, these samples were dried for $72 \mathrm{~h}$ at $80^{\circ} \mathrm{C}$ and weighed as dry weight. Water content (per fresh weight) was calculated as [(fresh weight — dry weight) $/$ (fresh weight) $] \times 100$. Some plants grown in the field were irrigated and some plants grown in pots were left unirrigated for 1-3 d before measurement.

\section{Statistical analyses}

Analysis of variance (ANOVA) was performed with the Statcel 2 add-in software for Excel. Means of inclination angle (leaflet and petiole) and water content (leaflet and soil) were compared by using the Tukey-Kramer multiple-range test at the $5 \%$ level of significance.

\section{RESULTS}

In 2008, the inclination angle of the petioles at $R_{5}$ was $80^{\circ}$ in 'Fukuyutaka', that of leaflets was a little less $\left(71.3^{\circ}\right)$, and those of 'Misato-zairai' ( $73.8^{\circ}$ in petiole, $66.3^{\circ}$ in leaflet) were less than those of 'Fukuyutaka' (Table 2). In 2009 (drier season), however, all angles were much less ('Fukuyutaka': $50.6^{\circ}$ in petiole, $46.9^{\circ}$ in leaflet; 'Misatozairai': $54.4^{\circ}$ in petiole, $58.1^{\circ}$ in leaflet): both cultivars showed significant differences between years. In 2011, irrigation significantly increased the inclination angle of leaflets ('Fukuyutaka': $73.8^{\circ}$ in irrigation, $57.5^{\circ}$ in unirrigation; 'Misato-zairai': $56.3^{\circ}$ in irrigation, $50.0^{\circ}$ in unirrigation), although there was no clear effect in petioles (Table 3 ).

After the water supply to the pots was stopped, the soil water content decreased gradually, although the leaflet water content initially increased slightly before then decreasing from $3 \mathrm{~d}$ (Fig. 1). The inclination angle of the petioles did not change until $3 \mathrm{~d}$, when it decreased substantially in both cultivars. The declines in leaflet water 
Table 2 Inclination angles $\left({ }^{\circ}\right)$ of the petioles and leaflets of 'Fukuyutaka' and 'Misato-zairai' in 2008 and 2009.

\begin{tabular}{lccc}
\hline Cultivar & Year & Petiole & Leaflet \\
\hline Fukuyutaka & 2008 & 80.0 & 71.3 \\
Misato-zairai & 2009 & 50.6 & 46.9 \\
& 2008 & 73.8 & 66.3 \\
& 2009 & 54.4 & 58.1 \\
\hline \multirow{2}{*}{ 2-Way ANOVA } & Cultivar (C) & n.s. & n.s. \\
& Year (Y) & $* * *$ & $* * *$ \\
& $\mathrm{C} \times$ Y & n.s. & n.s. \\
\hline
\end{tabular}

***, significant at 0.001. n.s., not significant.

Table 3 Inclination angles $\left({ }^{\circ}\right)$ of the petioles and leaflets of 'Fukuyutaka' and 'Misato-zairai' under irrigated and non-irrigated field conditions.

\begin{tabular}{lccc}
\hline Cultivar & Treatment & Petiole & Leaflet \\
\hline Fukuyutaka & Irrigation & 82.5 & 73.8 \\
& Non-irrigation & 74.4 & 57.5 \\
Misato-zairai & Irrigation & 69.4 & 56.3 \\
& Non-irrigation & 72.5 & 50.0 \\
\hline \multirow{2}{*}{ 2-Way ANOVA } & Cultivar (C) & n.s. & $*$ \\
& Irrigation (I) & n.s. & $*$ \\
& C $\times$ I & n.s. & n.s.
\end{tabular}

*, significant at 0.05 . n.s., not significant.

content and petiole inclination angle were steeper in 'Misato-zairai'. The inclination angle of leaflets showed a similar response to that of leaflet water content in both cultivars. In the field, the inclination angles of leaflets and petioles of both cultivars showed significant linear relationships with water content (Fig. 2). Since the range of water contents of these organs was narrow $(71-79 \% \mathrm{FW}$ in leaflets and $80-89 \% \mathrm{FW}$ in petioles), we ran a pot experiment to give a wider range of water contents $\left(62-85 \%\right.$ and $75^{-}$ $92 \%$, respectively). The results again showed significant linear relationships (Fig. 3). The inclination angle of leaflets also showed a significant linear relationship with that of petioles of both cultivars in both the field and pot experiments (Fig. 4).

\section{DISCUSSION}

A leaflet inclination angle before paraheliotropism contributes to stable seed production (Kokubun and Watanabe, 1981). Our results show that water condition is associated with the control of the inclination of leaflet and petiole.

'Misato-zairai' has a greater leaf area index and smaller inclination angles of leaflet and petiole than 'Fukuyutaka' (Nagasuga et al., 2011b). In 2008 and 2009, although two-way ANOVA did not detect any significant differences in inclination angles between cultivars (Table 2). However, the angles differed significantly between years (Table 2). The precipitation from sowing to $R_{5}$ in 2009 was half that in 2008 (Table 1). To evaluate whether the difference between years resulted from differences in water conditions, we ran an irrigation experiment in the field in 2011. Although the difference in soil water content between the treatments was not so large, irrigation increased the inclination angle of leaflets, particularly in
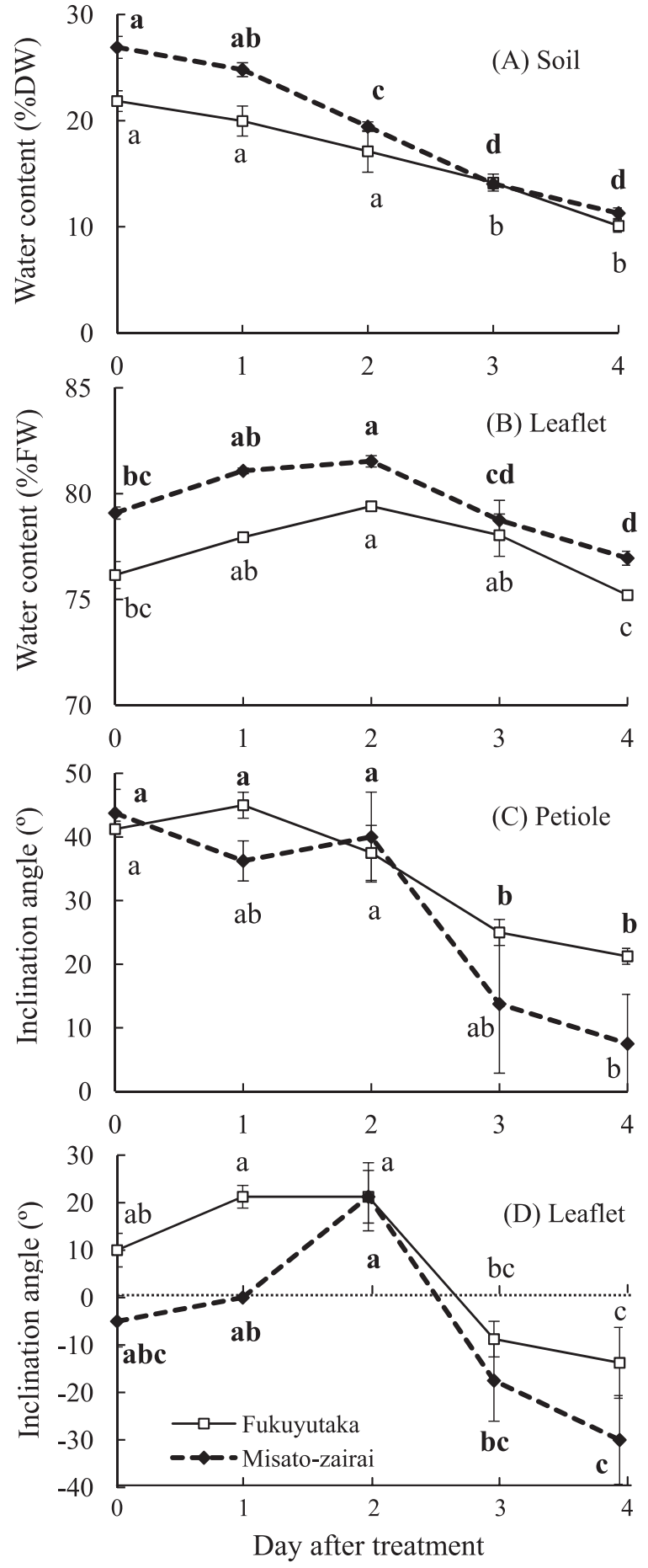

Fig. 1 Changes in water contents of soil (A) and leaflet (B), and inclination angle of petiole (C) and leaflet (D) after the stop of water supply to the pots. Vertical bars represent S.E. $(n=4)$. In each cultivar, means followed by the same letters are not significantly different $(P<0.05$, Tukey-Kramer test).

'Fukuyutaka' (Table 3). These results indicate that soil water condition is associated with changes in inclination angle.

Leaflet inclination (the angle between the secondary pulvinus and the leaflet) changes in response to soil water conditions during the daytime in soybean (Wang et al., 1994; Kao and Tsai, 1998), the common bean (Pastenes et 

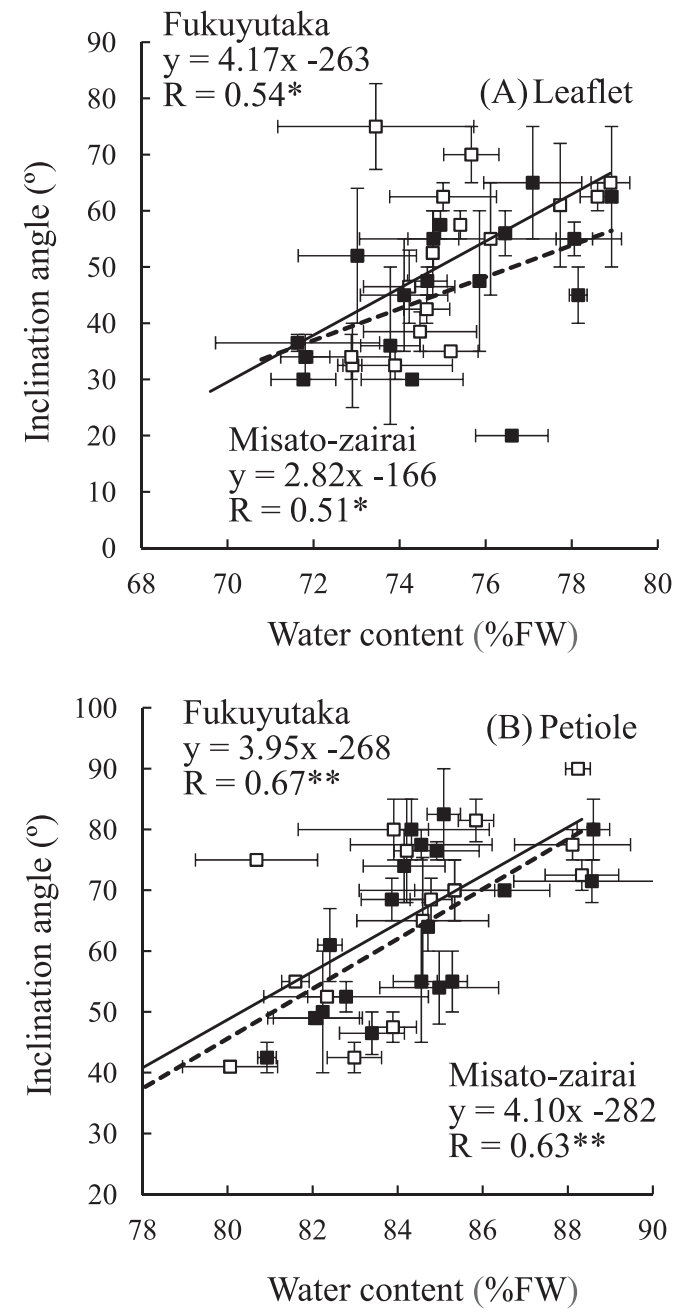

Fig. 2 Relationship between inclination angle and water content of the leaflet (A) and petiole (B) in 'Fukuyutaka' and 'Misato-zairai' grown in the field. $(* P<0.05$; ** $P$ $<0.01$., Tukey-Kramer test). $\square$ : Fukuyutaka, Misato-zairai.

al., 2004, 2005), and cowpea (Shackel and Hall, 1979). In this study, we withheld water to plants in pots to evaluate the response of inclination angles of petiole and leaflet, not paraheliotropism, to changes in soil water condition. Since we used very small pots for drought treatment, our pot trial could demonstrate the significant decline in soil water content only a few days after the withdrawal of water (Fig. 1). The leaf water content initially increased but then decreased from $3 \mathrm{~d}$ after the withdrawal of water (Fig. 1). Inclination angles showed a similar response (Fig. 1). 'Misato-zairai' showed larger changes in inclination angles, although the soil water content of the 'Misato-zairai' pots also decreased more (Fig. 1). These results suggest that 1) the inclination angles of petiole and leaflet decreased with the decline in the soil and leaflet water content, 2) the 'Misato-zairai' uses more water than 'Fukuyutaka' and 3) its leaflet inclination is easier to response to the soil water content.

The inclination angles of leaflets and petioles of both cultivars in the field decreased with the water content of these organs (Fig. 2). Since the soil water content in the
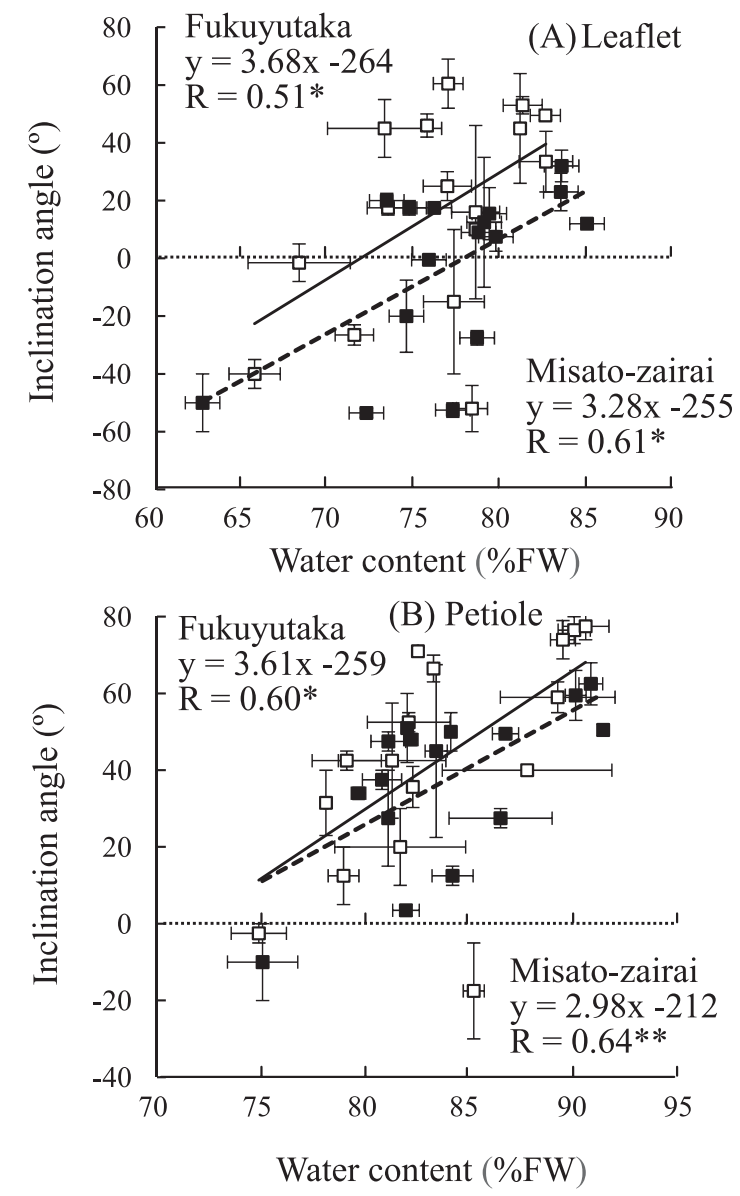

Fig. 3 Relationship between inclination angle and water content of leaflet and petiole in 'Fukuyutaka' and 'Misatozairai' grown in the pots. $(* P<0.05$; $* * P<0.01$., Tukey-Kramer test). $\square$ : Fukuyutaka, $\square$ : Misato-zairai.

field was replenished by rainfall, the range of these water contents was narrow (Fig. 2). Pot experiment could control the soil water condition and the plant age (measured as the number of nodes on the main stem, $8^{-12}$ ) close to the field (13-16) easily. Since water content per fresh weight differs among plant ages in spite of well water condition, pot experiment compensates the evaluation of water condition in the difference in plant age. The range of water content per fresh weight was larger in the pot experiment and there were significant linear relationships between inclination angle and water content in both experiments (Figs. 2, 3). These results indicate that the water contents of the leaflets and petioles affected these inclination.

The secondary pulvinus controls paraheliotropism (diurnal change in the angle between the secondary pulvinus and the leaflet) in legumes (Mayer et al., 1985; Gorton, 1990; Bielenberg et al., 2003; Ueda and Nakamura, 2007) through the turgor-based volume changes (in Phaseolus coccineus L., Mayer et al., 1985). Paraheliotropism responds to the short-term (minutes-days) environmental stimuli (Kao and Forth, 1992). In this study, changes in leaflet inclination in response to the soil and leaflet water contents paralleled changes in petiole inclination (Figs. 13 ), and the clear change in the angle between the secondary pulvinus and the leaflet was not found (data not shown). 

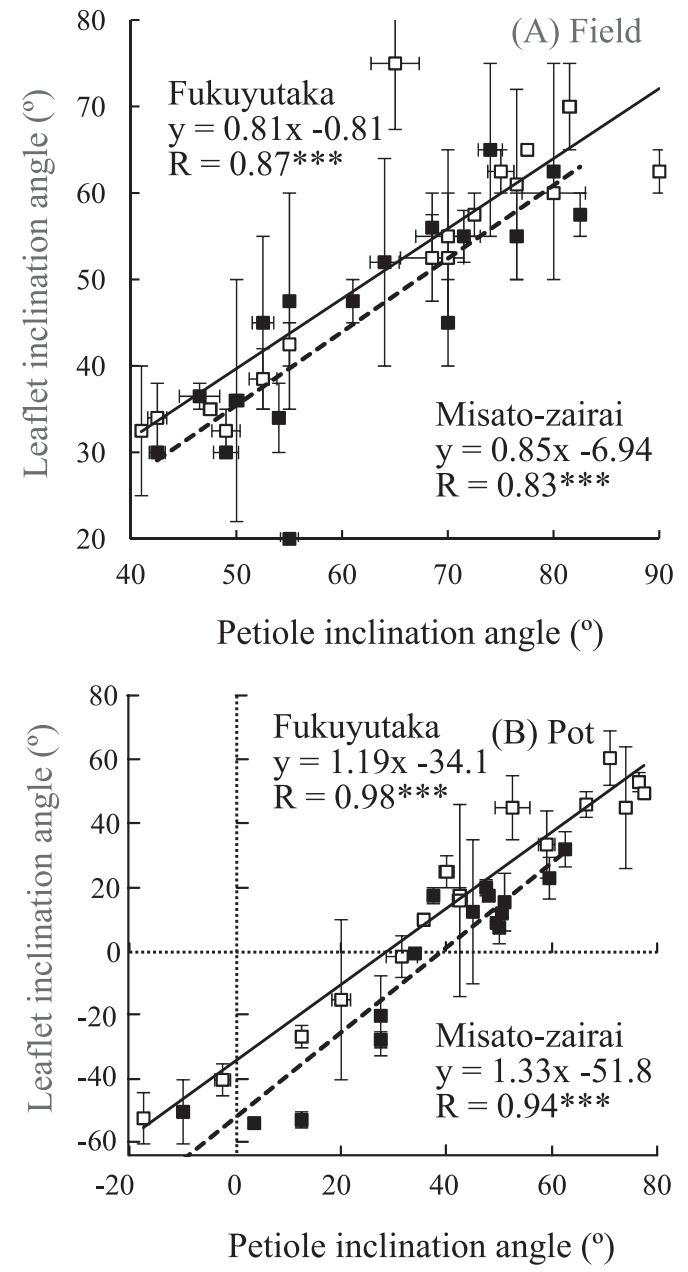

Fig. 4 Relationship between inclination angle of leaflet and petiole in 'Fukuyutaka' and 'Misato-zairai' grown in the field (A) and pots (B). (***P<0.001, TukeyKramer test). $\square$ : Fukuyutaka, $\square$ : Misato-zairai.

Since the soil water content in the field does not decreased significantly within a few days, the primary pulvinus should control the inclination angle of petioles and, as a result, leaflets in response to long-term (days-weeks) changes in water conditions.

Paraheliotropism protects legume leaves from high light intensity and high temperature (Kao and Tsai, 1998; Bielenberg et al., 2003; Pastenes et al., 2005). The decline in the leaflet and petiole inclination by long-term soil water shortage should increase the stresses of high light intensity and high temperature to the soybean leaflets. While, the decline in leaf area decreases plant transpiration and contributes to the survival under the severe soil water shortage. The primary pulvinus control of the leaflet inclination may increase the environmental stresses and, as a result, the death of leaflets for the survival under the long-term soil water shortage.

The linear relationships between inclination angle and water content (Fig. 3) and between inclination angles of leaflets and petioles (Fig. 4) were similar between cultivars. Gratani and Bombelli (2000) reported that among Cistus incanus (a semi-drought-deciduous shrub) and two evergreen sclerophyllous shrubs, Quercus ilex and Phillyrea latifolia, C. incanus, with the lowest specific leaf weight and total leaf thickness, also had the lowest leaf inclination angle. As the specific leaf weight of 'Misato-zairai' was often lower than that of 'Fukuyutaka' (Nagasuga et al., 2011b), its smaller inclination angles could be associated with genetic factors that control leaf thickness, particularly palisade parenchyma (Gratani and Bombelli, 2000), as well as with water content.

\section{REFERENCES}

Berg, V. S., Heuchelin, S. 1990. Leaf orientation of soybean seedlings. I. Effect of water potential and photosynthetic photon flux density on paraheliotropism. Crop Sci. 30: 631-638.

Bielenberg, D. G., Miller, J. D., Berg, V. S. 2003. Paraheliotropism in two Phaseolus species: combined effects of photon flux density on paraheliotropism. Env. Exp. Bot. 49: 95-105.

Blad, B. L., Baker, D. G. 1972. Orientation and distribution of leaves within soybean canopies. Agron. J. 64: 26-29.

Fehr, W. R., Caviness, C. E. 1977. Stages of soybean development. Iowa Coop. Ext. Serv. Spec. Rep. 80.

Forseth, I. N., Ehleringer, J. R. 1980. Solar tracking response to drought in a desert annual. Oecologia 44: 159-163.

Gorton, H. L. 1990. Stomates and pulvini: a comparison of two rhythmic, turgor-mediated movement systems. In: "The Pulvinus: Mmotor Organ for Leaf Movement." Satter, R. L., Gorton, H. L., Vogelmann, T. C. American Society of Plant Physiologists, Rockville, MD, USA. p 228-237.

Gratani, L., Bombelli, A. 2000. Correlation between leaf age and other leaf traits in three Mediterranean maquis shrub species: Quercus ilex, Phillyrea latifolia and Cistus incanus. Environ. Exp. Bot. 43: 141-153.

Johnston, T. J., Pendleton, J. W., Peter, D. B., Hicks, D. R. 1969. Influence of supplemental light on apparent photosynthesis, yield and yield components of soybeans (Glycine $\max$ L.). Crop Sci. 9: 577-581.

Kao, W. Y., Forth, I. N. 1992. Responses of gas exchange and phototropic leaf orientation in soybean to soil water availability, leaf water potential, air temperature, and photosynthetic photon flux. Environ. Exp. Bot. 32: 153-161.

Kao, W. Y., Tsai, T. T. 1998. Tropic leaf movements, photosynthetic gas exchange, leaf $\delta^{13} \mathrm{C}$ and chlorophyll a fluorescence of three soybean species in response to water availability. Plant Cell Environ. 21: 1055-1062.

Kokubun, M., Watanabe, K. 1981. Analysis of the yielddetermining process of field-grown soybeans in relation to canopy structure. II. Effect of plant type alteration on solar radiation interception and yield components. Jpn. J. Crop Sci. 50: 311-317.

Li, Z. K., Paterson, A. H., Pinson, S. R. M., Khush, G. S. 1998. A major gene, Tal, and QTLs affecting tiller and leaf angles in rice. Rice Genet. Newsl. 15: 154-156.

Li, Z. K., Paterson, A. H., Pinson, S. R. M., Stansel, J. W. 1999. RFLP facilitated analysis of tiller and leaf angles in rice (Oryza sativa L.). Euphytica 9: 79-84.

Mayer, W. E., Flach, D., Raju, M. V. S., Starrach, N., Wiech, E. 1985. Mechanics of circadian pulvini movements in Phaseolus coccineus L. Planta 163: 381-390.

Nagasuga, K., Kaji, H., Fukunaga, A., Kadowaki, M., Uchida, S, Nose, S., Umezaki, T. 2011a. Non-destructive evaluation of water status of leaflet and petiole in soybean plants by moisture checker. (in Japanese with English abstract) Ann. Field Res. Tech. Mie Univ. 10: 1-10.

Nagasuga, K., Uchida, S., Kaji, H., Hayakawa, Y., Nose, S., 


\section{K. NAGASUGA ET AL.}

Umezaki, T. 2011b. Seed production, dry matter production, and light intercepting characteristics of soybean cultivar 'Misato-zairai'. (in Japanese with English abstract) Jpn. J. Crop Sci. 80: 326-332.

Oosterhuis, D. M., Walker, S., Eastham, J. 1985. Soybean leaflet movements as an indicator of crop water stress. Crop Sci. 25: 1101-1106.

Pastenes, C., Pimentel, P., Lillo, J. 2004. Paraheliotropism can protect water-stressed bean (Phaseolus vulgaris L.) plants against photoinhibition. J. Plant Physiol. 161: 1315-1323.

Pastenes, C., Pimentel, P., Lillo, J. 2005. Leaf movements and photoinhibition in relation to water stress in field-grown beans. J. Exp. Bot. 56: 425-433.

Saitoh, K., Yonetani, K., Murota, T., Kuroda, T. 2002. Effects of flag leaves and panicles on light interception and canopy photosynthesis in high-yielding rice cultivars. Plant Pro. Sci. 5: $275-280$.

Sakamoto, C. M., Shaw, R. H. 1967. Light distribution in field soybean canopies. Agron. J. 59: 7-9.

Sakamoto, T., Morinaka, Y., Ohnishi, T., Sunohara, H., Fujioka, S., Ueguchi-Tanaka, M., Mizutani, M., Sakata, K., Takatsuto, S., Yoshida, S., Tanaka, H., Kitano, H., Matsuoka, M. 2006.
Erect leaves caused by brassinosteroid deficiency increase biomass production and grain yield in rice. Nat. Biotechnol. 24: $105-109$.

Shackel, K. A., Hall, A. E. 1979. Reversible leaflet movements in relation to drought adaptation of cowpeas, Vigna unguiculata (L.) Walp. Aust. J. Plant Physiol. 6: 265-276.

Shaw, R. H., Weber, C. R. 1967. Effects of canopy arrangements on light interception and yield of soybeans. Agron. J. 59: $155-159$.

Sinclair, T. R., Sheehy, J. E. 1999. Erect leaves and photosynthesis in rice. Science 283: 1455.

Soda, K., Ookawa, T., Motobayashi, T., Hirasawa, T. 2010. Quick estimation of varietal differences in light extinction coefficient of the canopy through the inclination angle of leaf blade in rice. (in Japanese with English abstract) Jpn. J. Crop Sci. 79: $174-183$.

Ueda, M., Nakamura, Y. 2007. Chemical basis of plant leaf movement. Plant Cell Physiol. 48: 900-907.

Wang, P., Isoda, A., Wei, G., Yoshimura, T. 1994. Growth and adaptation of soybean cultivars under water stress conditions. II. Effects of leaf movement on radiation interception. Jpn. J. Crop Sci. 63: 699-705. 